\title{
Expression of Thymidine Phosphorylase in Lymph Nodes Involved with Mycosis Fungoides and Sézary Syndrome
}

\author{
Xingcao Nie, ${ }^{1}$ Rekha Bhat, ${ }^{1}$ Essel Dulaimi Al-Saleem, ${ }^{1}$ Eric C. Vonderheid, ${ }^{2}$ and J. Steve Hou ${ }^{1}$ \\ ${ }^{1}$ Department of Pathology, Drexel University College of Medicine, 245 N. 15th Street, Mail Stop 435, Philadelphia, PA 19102, USA \\ ${ }^{2}$ Johns Hopkins Medical Institutes, Baltimore, MD, USA \\ Correspondence should be addressed to J. Steve Hou, j.hou@drexelmed.edu
}

Received 9 June 2011; Revised 1 September 2011; Accepted 2 September 2011

Academic Editor: Michael L. Grossbard

Copyright ( 2011 Xingcao Nie et al. This is an open access article distributed under the Creative Commons Attribution License, which permits unrestricted use, distribution, and reproduction in any medium, provided the original work is properly cited.

\begin{abstract}
Thymidine phosphorylase may be overexpressed in both neoplastic cells and tumor stromal cells in a variety of malignancies. Our study explores thymidine phosphorylase expression in lymph nodes (LNs) from patients with mycosis fungoides (MF) or Sézary syndrome (SS). In MF/SS, the LNs may have a pathologic diagnosis of either dermatopathic lymphadenopathy (LN-DL) or involvement by MF/SS (LN-MF). We performed immunohistochemical staining on MF/SS lymph nodes using antibodies to thymidine phosphorylase, CD68, CD21, CD3, and CD4. In both LN-DL and benign nodes, thymidine phosphorylase staining was noted only in macrophages, dendritic cells, and endothelial cells. In LN-MF, thymidine phosphorylase expression was also noted in subsets of intermediate to large neoplastic T cells. Concurrent CD68, CD21, CD3, and CD4 staining supported the above observations. Similar results were noted in the skin and in LN-MF with large cell transformation. Other T-cell lymphomas were also examined (total 7 cases); only enteropathy-type T-cell lymphoma (1 case) showed TP positivity in neoplastic T lymphocytes. We demonstrated that thymidine phosphorylase staining is present in neoplastic T cells in mycosis fungoides. The exact mechanism needs further investigation.
\end{abstract}

\section{Introduction}

Mycosis fungoides (MF) and Sézary syndrome (SS) are the most common types of cutaneous T-cell lymphomas and represent clonal proliferations of neoplastic $\mathrm{CD} 4^{+} \mathrm{T}$ cells. MF initially develops in an indolent fashion as a skin-confined disease. However, with progressive disease, malignant $\mathrm{T}$ cells involve skin-associated lymph nodes (LNs), thereby indicating a higher clinical stage [1]. The presence of circulating neoplastic cells in the peripheral blood is the hallmark of SS. Lymphadenopathy in MF/SS ranges from dermatopathic lymphadenopathy (DL), a reactive pattern associated with various chronic skin diseases, to clearcut involvement by malignant $\mathrm{T}$ cells that results in partial or complete effacement of lymph node structure (MF-LN). Smaller numbers of atypical or neoplastic cells may be found in DL, but the prognostic significance is unclear [2].

Various mechanisms have been implicated in the complexity of tumorigenesis, including imbalance of subsets of T- regulatory cells and cytokine levels [3-5] and dysregulation of chemokine receptors, including CCR4, CXCR4, CCR10 [6-8], and P16 [9]. However, the mechanism of tumorigenesis has not been well established. Thymidine phosphorylase (TP), also known as platelet-derived endothelial cell growth factor, may be overexpressed in both neoplastic cells and tumor stromal cells in a variety of cancers, including breast [10], colorectal [11], gastric [12], esophageal [13], lung [14], and bladder [15]. TP is thought to promote tumorigenesis by inducing tumor cell growth through both inhibition of the apoptosis pathway [16-19] and tumor angiogenesis via the PI3K-mTOR (phosphoinositide 3-kinase-mammalian target of rapamycin) pathway [20]. In addition, TP expression in neoplastic cells can be used as a biomarker to predict response to chemotherapy and survival in esophageal squamous cell carcinoma, breast cancer, and other cancers [21, 22]. However, few studies regarding the role of TP in hematopoietic malignancy have been reported. We studied TP expression in MF-LN. 


\section{Materials and Methods}

Experimental protocols were approved by the Institutional Review Board of Drexel University College of Medicine. Archived paraffin blocks with LNs from 51 patients with MF and SS (1991-2010) were used to construct a tissue microarray. Thirty-four of $51 \mathrm{MF} / \mathrm{SS}$ patients had a pathologic diagnosis of DL and 17 had partially or completely effaced LNs by MF or SS. Immunohistochemical (IHC) staining using antibodies to TP, CD68, CD21, CD3, and CD4 was performed. Nine cases of benign LNs were included as control. Archived unstained skin slides were also used to test TP expression from patients with MF in skin-confined stage (5 cases), MF-LN with large cell transformation (1 case), extranodal NK/T-cell lymphoma (1 case), peripheral T-cell lymphoma (2 cases), enteropathy-type T-cell lymphoma (1 case), angioimmunoblastic T-cell lymphoma (2 cases), and syringotropic cutaneous T-cell lymphoma ( 1 case).

For IHC staining, the slides were deparaffinized and rehydrated in a series of alcohol. IHC staining was performed using an automated system (Dako Autostainer, Universal Staining System Autostainer, Carpinteria, Calif). The primary antibodies used in this study were TP $(1: 1000$; Novus Biologicals, Littleton, Colo), CD3 (1:100; Dako), CD4 (1: 10; Dako), CD68 (1:2000; Dako), and CD21 (1: 50; Vector, Burlingame, Calif), used for tissue microarray blocks. Markers used for skin slides were CD4 and TP; TP was used as a marker for all other T-cell lymphomas.

\section{Results and Discussion}

In control LNs, TP staining was noted only in macrophages, dendritic cells, and endothelial lining cells, with a cytoplasmic and nuclear staining pattern. Small lymphocytes were negative for TP. A similar TP IHC staining pattern was noted in DL. Positive TP immunostaining was noted in $30 \%$ to $80 \%$ of intermediate to large neoplastic T cells in all MF-LN cases with a predominantly cytoplasmic staining pattern (Figure 1). Small lymphocytes were negative for TP, and macrophages, dendritic cells, and endothelial lining cells were again positive for TP. Concurrent CD68 and CD21 staining supported the above observations (Figure 1). IHC staining in MF-skin (Figures 2(a)-2(c)) and in MFLN with large cell transformation (Figure 2(d)) showed a similar staining pattern. Positive TP staining was noted in the neoplastic $\mathrm{T}$ cells in one case of enteropathy-type Tcell lymphoma (Figure 3). In other lymphoma cases (extranodal NK/T-cell lymphoma, peripheral T-cell lymphoma, angioimmunoblastic T-cell lymphoma, and syringotropic cutaneous T-cell lymphoma) positive TP staining was only noted in macrophages and endothelial cells.

Thymidine phosphorylase was found to be present in benign tissue, such as spleen, liver, lymph nodes, esophagus, and rectum, and in a variety of cells, including macrophages, stromal cells, glial cells, endothelial cells, and reticulocytes, with a cytoplasmic or nuclear pattern $[23,24]$. Studies have shown that TP is overexpressed in both neoplastic cells and tumor stromal cells in a variety of malignancies such as breast, colorectal, gastric, esophageal, lung, and bladder. We demonstrated that TP expression is present not only in macrophages, dendritic meshworks, and endothelial lining cells but also in intermediate to large neoplastic $\mathrm{T}$ lymphocytes.

To our knowledge, 2 previous studies have reported on TP expression in hematopoietic malignancies. In 1990, Yoshimura et al. [24], using immunoblotting, demonstrated higher TP expression in tissues from patients with T- and B-cell malignant lymphomas than from those with lymphoblastic and myeloblastic leukemias. However, they did not determine which cells expressed TP in the hematopoietic malignancies. In 1997 Doussis-Anagnostopoulou et al. [25] used IHC staining to test TP expression in a variety of tissues from patients with hematopoietic malignancies. Malignancies tested included Hodgkin's lymphoma (20 cases), small lymphocytic lymphoma ( 2 cases), mantle cell lymphoma (1 case), follicular lymphoma (10 cases), diffuse large B-cell lymphoma (8 cases), peripheral T-cell lymphoma (7 cases), intestinal T-cell lymphoma (1 case), and anaplastic large Tcell lymphoma (1 case). TP expression was noted only in the meshwork of dendritic cells, macrophages, and endothelial cells but not in neoplastic cells. The authors commented that the expression of TP in dendritic cells and macrophages might be due to cytokine production and dysregulation contributing to the tumor microenvironment.

We have demonstrated that TP expression is present in neoplastic T cells in LNs, skin involved with MF or SS (Table 1). This phenomenon may be due to changes intrinsic to the tumor cells themselves, or it may reflect interactions between the tumor microenvironment and the lymphoma cells. The exact mechanism of increased TP expression in lymphoma cells needs further investigation and may have therapeutic implications. Data are scarce regarding TP expression in other neoplastic T-cell lymphomas, and further study would be worthwhile.

\section{Abbreviations}

$\begin{array}{ll}\text { DL: } & \text { Dermatopathic lymphadenopathy } \\ \text { IHC: } & \text { Immunohistochemical } \\ \text { LN: } & \text { Lymph node } \\ \text { MF: } & \text { Mycosis fungoides } \\ \text { PI3K-mTOR: } & \text { Phosphoinositide 3-kinase-mammalian } \\ & \text { target of rapamycin } \\ \text { SS: } & \text { Sézary syndrome } \\ \text { TP: } & \text { Thymidine phosphorylase. }\end{array}$

\section{Authors' Contribution}

X. Nie and R. Bhat constructed tissue microarray blocks. X. Nie performed the experiment and wrote the paper. R. Bhat and E. D. Al-Saleem gave suggestions for the paper. E. C. Vonderheid and J. S. Hou are coprincipal investigators of the study, recruited the patients, and coordinated the research.

\section{Conflict of Interests}

The authors declare no competing financial interests. 


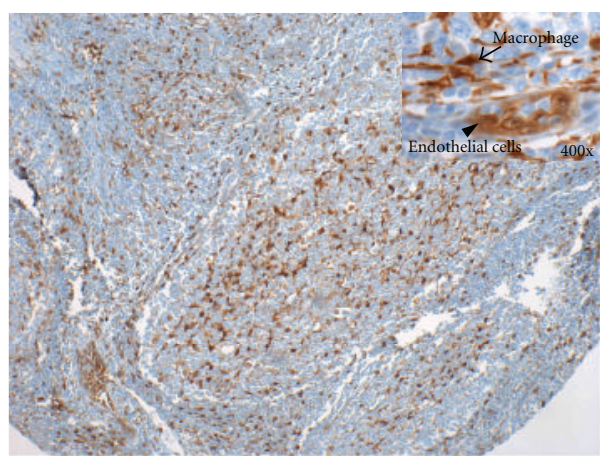

(a)

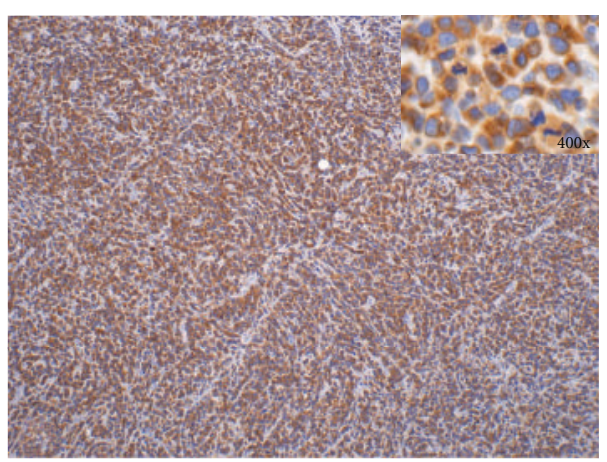

(c)

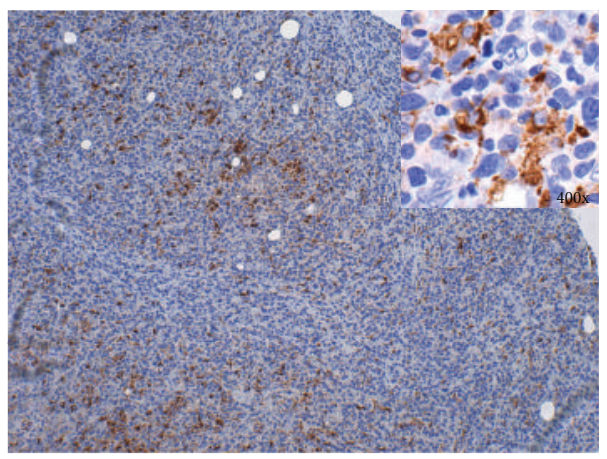

(e)

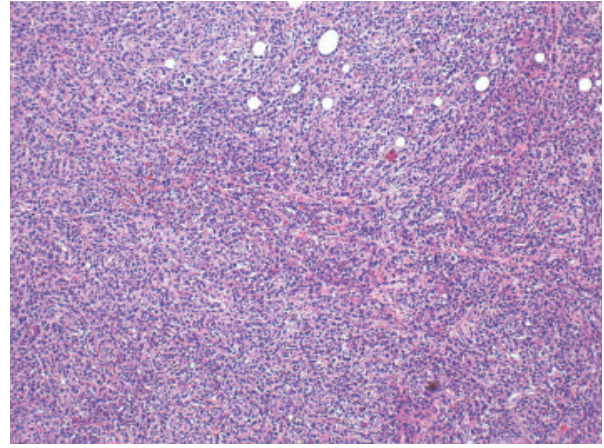

(b)

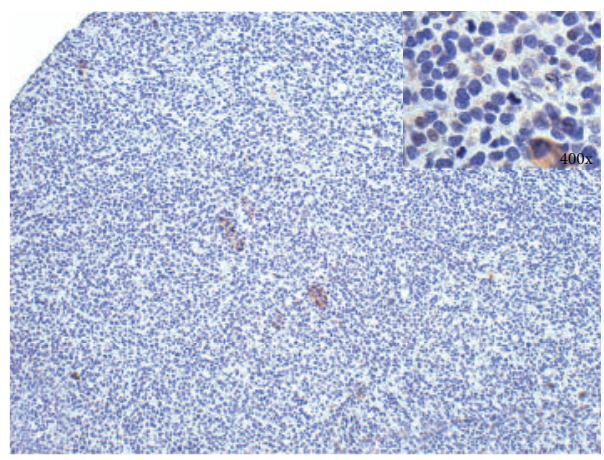

(d)

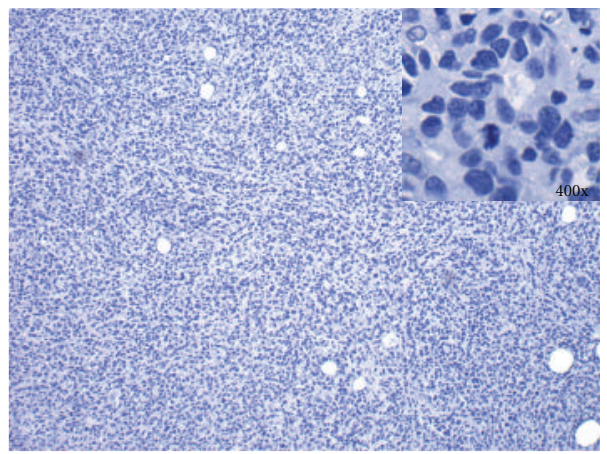

(f)

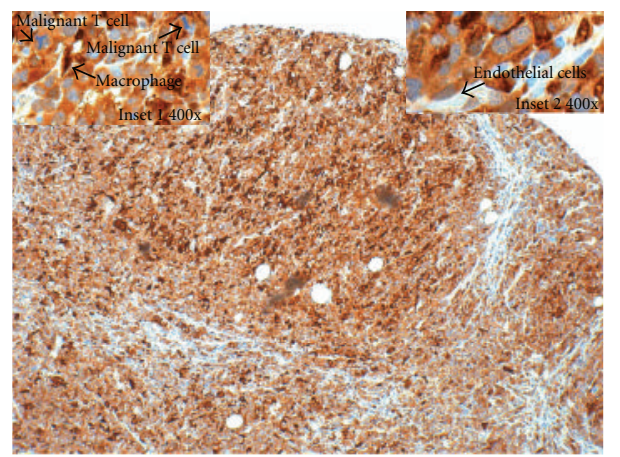

(g)

FIGURE 1: Immunohistochemical staining of thymidine phosphorylase (TP) expression and related markers in benign lymph node (a) and in lymph node with malignant mycosis fungoides/Sézary syndrome cells (LN-MF) (b-g). (a) In benign lymph node, TP expression highlights the meshwork of macrophages (arrow in inset; 400x) and endothelial cells (arrowhead in inset; 400x). (b) LN-MF: hematoxylin and eosin (H\&E) stain. (c) CD3 highlights the malignant T cells and reactive T cells in LN-MF. (d) CD4 is weakly expressed in the malignant T cells in LN-MF. (e) CD68 highlights the macrophages in LN-MF. (f) CD21 is negative in this case of LN-MF. (g) TP highlights the macrophages (cytoplasmic/nuclear pattern, arrowhead in inset $1 ; 400 \mathrm{x}$ ) and the malignant $\mathrm{T}$ cells (cytoplasmic pattern, arrow in inset 2 ; 400x) in a cytoplasmic staining pattern. Multiple mitotic figures are also noted in the malignant T cells. Images are from an Olympus BX41 microscope (Olympus Corp., Tokyo, Japan) processed with Qcapture Pro 5.1 (QImaging, Surrey, BC, Canada). 


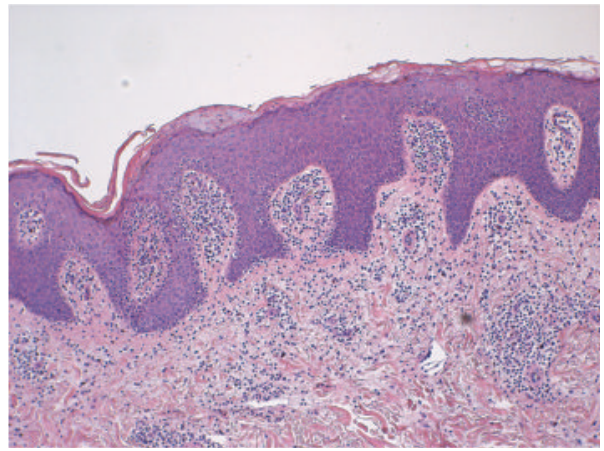

(a)

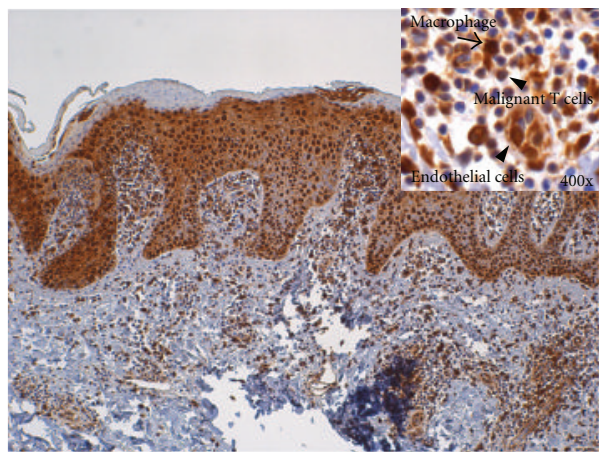

(c)

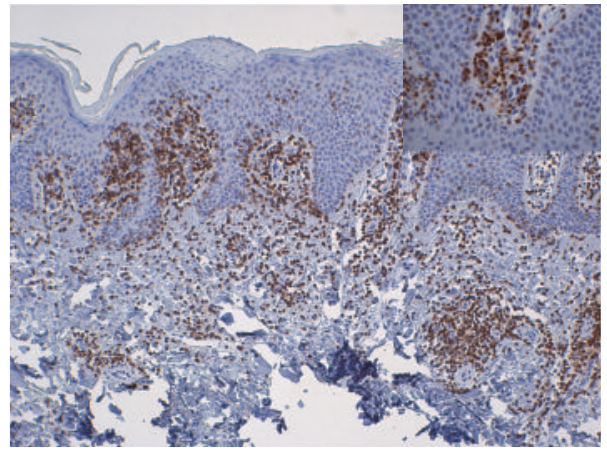

(b)

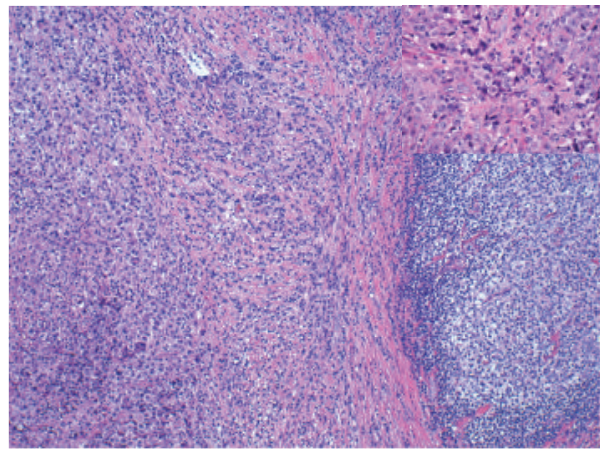

(d)

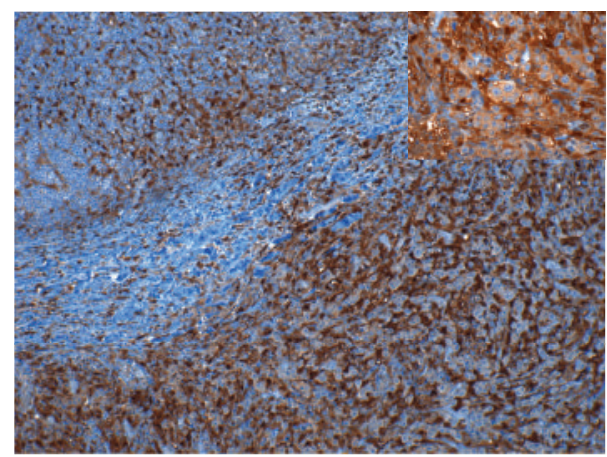

(e)

FIGURE 2: Immunohistochemical stain of thymidine phosphorylase (TP) expression and related markers in skin-involved mycosis fungoides (MF-skin) and in a case of mycosis fungoides/Sézary syndrome cells with involved lymph nodes (LN-MF) with large cell transformation. (a) MF-skin: hematoxylin and eosin (H\&E) stain. (b) MF-skin: CD4 highlights the malignant T cells in the epidermis. (c) MF-skin: TP expression is noted in malignant T cells (arrow in inset; 400x), squamous cells, and endothelial cells (arrowhead in inset; 400x). (d) An MF lymph node with large cell transformation is demonstrated: H\&E stain. (e) TP stain shows positive immunoactivity in the transformed large neoplastic T cells (arrow in inset; 400x); macrophages are indicated by arrow in inset (400x). Images are from an Olympus BX41 microscope (Olympus Corp., Tokyo, Japan) processed with Qcapture Pro 5.1 (QImaging, Surrey, BC, Canada).

TABLE 1: Thymidine phosphorylase immunohistochemical stain (cytoplasmic/nuclear).

\begin{tabular}{lcccc}
\hline & Small lymphocytes & Neoplastic cells & Macrophages and dendritic cells & Endothelial cells \\
\hline Benign LN & Negative & N/A & Positive & Positive \\
MF-LN & Negative & Positive & Positive & Positive \\
\hline
\end{tabular}

LN: lymph nodes; MF-LN: lymph nodes involved with mycosis fungoides or Sézary syndrome. 


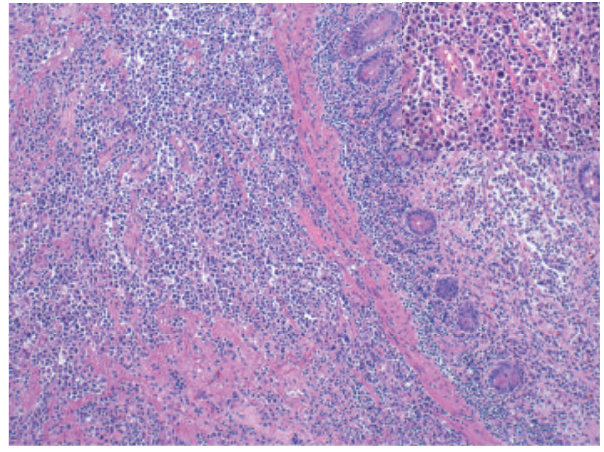

(a)

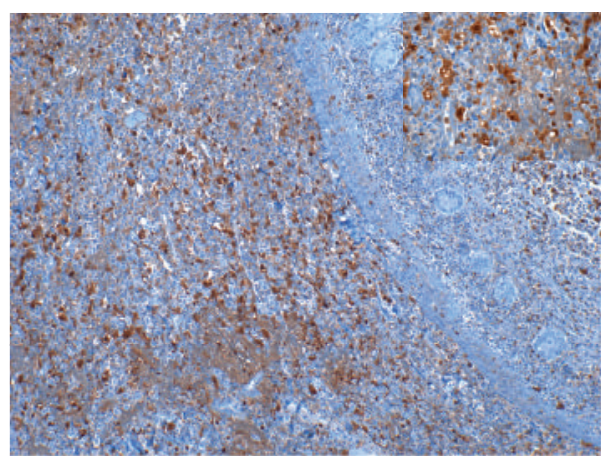

(b)

FIGURE 3: Immunohistochemical stain of thymidine phosphorylase (TP) expression in a gastrointestinal biopsy specimen from a patient with enteropathy-type T-cell lymphoma. (a) Hematoxylin and eosin stain. (b) TP stain highlights neoplastic T cells (arrow in inset; 400x). Images are from an Olympus BX41 microscope (Olympus Corp., Tokyo, Japan) processed with Qcapture Pro 5.1 (QImaging, Surrey, BC, Canada).

\section{Acknowledgments}

This work was supported by the Department of Pathology, Drexel University College of Medicine (DUCOM). The authors thank the Cancer Center at Hahnemann University Hospital, Sharon Cavone (H. T., DUCOM) and Tammy Haines (Hahnemann University Hospital) for IHC technical support, and Diana Winters of Academic Publishing Services (DUCOM) for editorial assistance. These findings were presented in part in poster form at the annual meeting of the United States and Canadian Academy of Pathology, San Antonio, Tex, February 26-March 4, 2011.

\section{References}

[1] The International Agency for Research on Cancer, S. Swerdlow, E. Campo et al., WHO Classification of Tumours of Haematopoietic and Lymphoid Tissue, International Agency for Research on Cancer, Lyon, France, 4th edition, 2008.

[2] E. C. Vonderheid, L. W. Diamond, S.-M. Lai, F. Au, and M. A. Dellavecchia, "Lymph node histopathologic findings in cutaneous T-cell lymphoma. A prognostic classification system based on morphologic assessment," American Journal of Clinical Pathology, vol. 97, no. 1, pp. 121-129, 1992.

[3] B. F. Chong, A. J. Wilson, H. M. Gibson et al., "Immune function abnormalities in peripheral blood mononuclear cell cytokine expression differentiates stages of cutaneous T-cell lymphoma/mycosis fungoides," Clinical Cancer Research, vol. 14, no. 3, pp. 646-653, 2008.

[4] A. Cirée, L. Michel, S. Camilleri-Bröet et al., "Expression and activity of IL-17 in cutaneous T-cell lymphomas (mycosis fungoides and Sezary syndrome)," International Journal of Cancer, vol. 112, no. 1, pp. 113-120, 2004.

[5] S. D. Doherty, X. Ni, C. B. Doherty et al., "Abnormal expression of interleukin-23 in mycosis fungoides/Sézary syndrome lesions," Archives of Dermatological Research, vol. 298, no. 7, pp. 353-356, 2006.

[6] K. Ferenczi, R. C. Fuhlbrigge, J. L. Pinkus, G. S. Pinkus, and T. S. Kupper, "Increased CCR4 expression in cutaneous T cell lymphoma," Journal of Investigative Dermatology, vol. 119, no. 6, pp. 1405-1410, 2002.
[7] M. G. Narducci, E. Scala, A. Bresin et al., "Skin homing of Sézary cells involves SDF-1-CXCR4 signaling and downregulation of CD26/dipeptidylpeptidase IV," Blood, vol. 107, no. 3, pp. 1108-1115, 2006.

[8] M. Notohamiprodjo, S. Segerer, R. Huss et al., "CCR10 is expressed in cutaneous T-cell lymphoma," International Journal of Cancer, vol. 115, no. 4, pp. 641-647, 2005.

[9] I. C. Navas, P. L. Ortiz-Romero, R. Villuendas et al., "p16(INK4a) gene alterations are frequent in lesions of mycosis fungoides," American Journal of Pathology, vol. 156, no. 5, pp. 1565-1572, 2000.

[10] E. Ioachim, "Thymidine phoshorylase expression in breast cancer: the prognostic significance and its association with other angiogenesis related proteins and extracellular matrix components," Histology and Histopathology, vol. 23, no. 2, pp. 187-196, 2008.

[11] A. Giatromanolaki, E. Sivridis, and M. I. Koukourakis, "Angiogenesis in colorectal cancer: prognostic and therapeutic implications," American Journal of Clinical Oncology, vol. 29, no. 4, pp. 408-417, 2006.

[12] T. Yoshikawa, K. Suzuki, O. Kobayashi et al., "Thymidine phosphorylase/platelet-devived endothelial cell growth factor is upregulated in advanced solid types of gastric cancer," British Journal of Cancer, vol. 79, no. 7-8, pp. 1145-1150, 1999.

[13] M. Ikeguchi, T. Sakatani, T. Ueta et al., "The expression of thymidine phosphorylase suppresses spontaneous apoptosis of cancer cells in esophageal squamous cell carcinoma," Pathobiology, vol. 69, no. 1, pp. 36-43, 2001.

[14] K. J. O’Byrne, M. I. Koukourakis, A. Giatromanolaki et al., "Vascular endothelial growth factor, platelet-derived endothelial cell growth factor and angiogenesis in non-small-cell lung cancer," British Journal of Cancer, vol. 82, no. 8, pp. 1427-1432, 2000.

[15] N. Nonomura, Y. Nakai, M. Nakayama et al., "The expression of thymidine phosphorylase is a prognostic predictor for the intravesical recurrence of superficial bladder cancer," International Journal of Clinical Oncology, vol. 11, no. 4, pp. 297-302, 2006.

[16] R. Ikeda, Y. Tajitsu, K. Iwashita et al., "Thymidine phosphorylase inhibits the expression of proapoptotic protein BNIP3," Biochemical and Biophysical Research Communications, vol. 370, no. 2, pp. 220-224, 2008. 
[17] H. C. Jeung, X. F. Che, M. Haraguchi et al., "Thymidine phosphorylase suppresses apoptosis induced by microtubuleinterfering agents," Biochemical Pharmacology, vol. 70, no. 1, pp. 13-21, 2005.

[18] S. Mori, S. Takao, R. Ikeda et al., "Thymidine phosphorylase suppresses Fas-induced apoptotic signal transduction independent of its enzymatic activity," Biochemical and Biophysical Research Communications, vol. 295, no. 2, pp. 300-305, 2002.

[19] E. Okamoto, M. Osaki, S. Kase, H. Adachi, N. Kaibara, and H. Ito, "Thymidine phosphorylase expression causes both the increase of intratumoral microvessels and decrease of apoptosis in human esophageal carcinomas," Pathology International, vol. 51, no. 3, pp. 158-164, 2001.

[20] Y. Nakajima, R. Madhyastha, and M. Maruyama, "2-Deoxy-Dribose, a downstream mediator of thymidine phosphorylase, regulates tumor angiogenesis and progression," Anti-Cancer Agents in Medicinal Chemistry, vol. 9, no. 2, pp. 239-245, 2009.

[21] S. J. Lee, Y. L. Choi, Y. H. Park et al., "Thymidylate synthase and thymidine phosphorylase as predictive markers of capecitabine monotherapy in patients with anthracyclineand taxane-pretreated metastatic breast cancer," Cancer Chemotherapy and Pharmacology, vol. 68, no. 3, pp. 743-51, 2011.

[22] S. Lee, Y. H. Park, K. H. Kim et al., "Thymidine synthase, thymidine phosphorylase, and excision repair cross complementation group 1 expression as predictive markers of capecitabine plus cisplatin chemotherapy as first-line treatment for patients with advanced oesophageal squamous cell carcinoma," British Journal of Cancer, vol. 103, no. 6, pp. 845$851,2010$.

[23] S. B. Fox, A. Moghaddam, M. Westwood et al., "Plateletderived endothelial cell growth factor/thymidine phosphorylase expression in normal tissues: an immunohistochemical study," Journal of Pathology, vol. 176, no. 2, pp. 183-190, 1995.

[24] A. Yoshimura, Y. Kuwazuru, T. Furukawa, H. Yoshida, K. Yamada, and S. Akiyama, "Purification and tissue distribution of human thymidine phosphorylase; high expression in lymphocytes, reticulocytes and tumors," Biochimica et Biophysica Acta, vol. 1034, no. 1, pp. 107-113, 1990.

[25] I. A. Doussis-Anagnostopoulou, S. Remadi, H. Turley et al., "Platelet-derived endothelial cell growth factor/thymidine phosphorylase immunohistochemical expression in lymphoid tissue and lymphoid malignancies," Human Pathology, vol. 28, no. 10, pp. 1146-1151, 1997. 


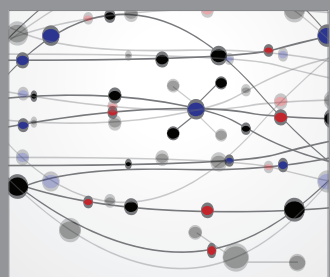

The Scientific World Journal
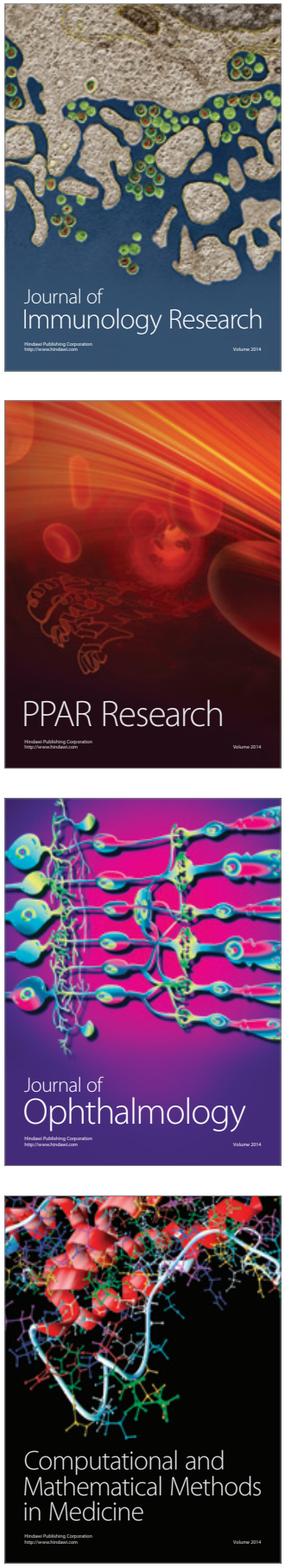

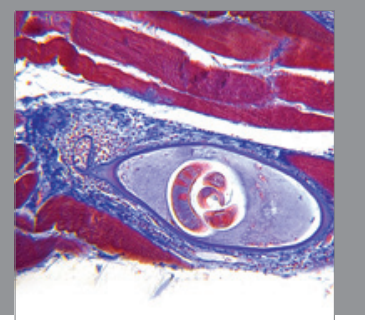

Gastroenterology

Research and Practice
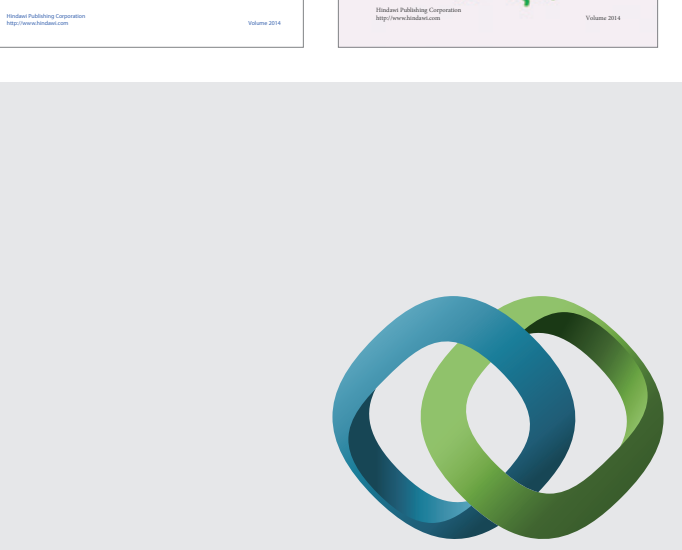

\section{Hindawi}

Submit your manuscripts at

http://www.hindawi.com
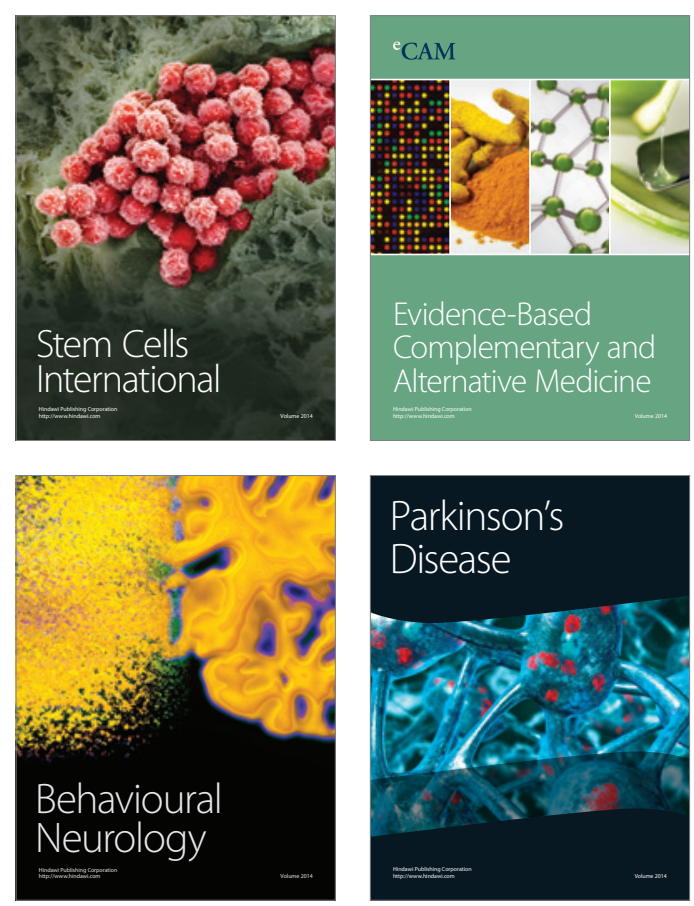

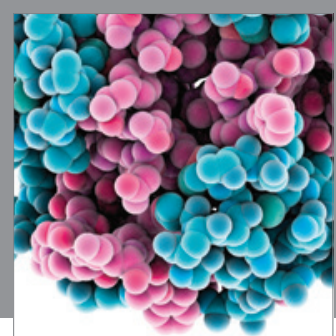

Journal of
Diabetes Research

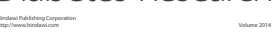

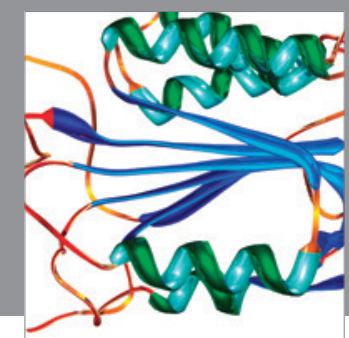

Disease Markers
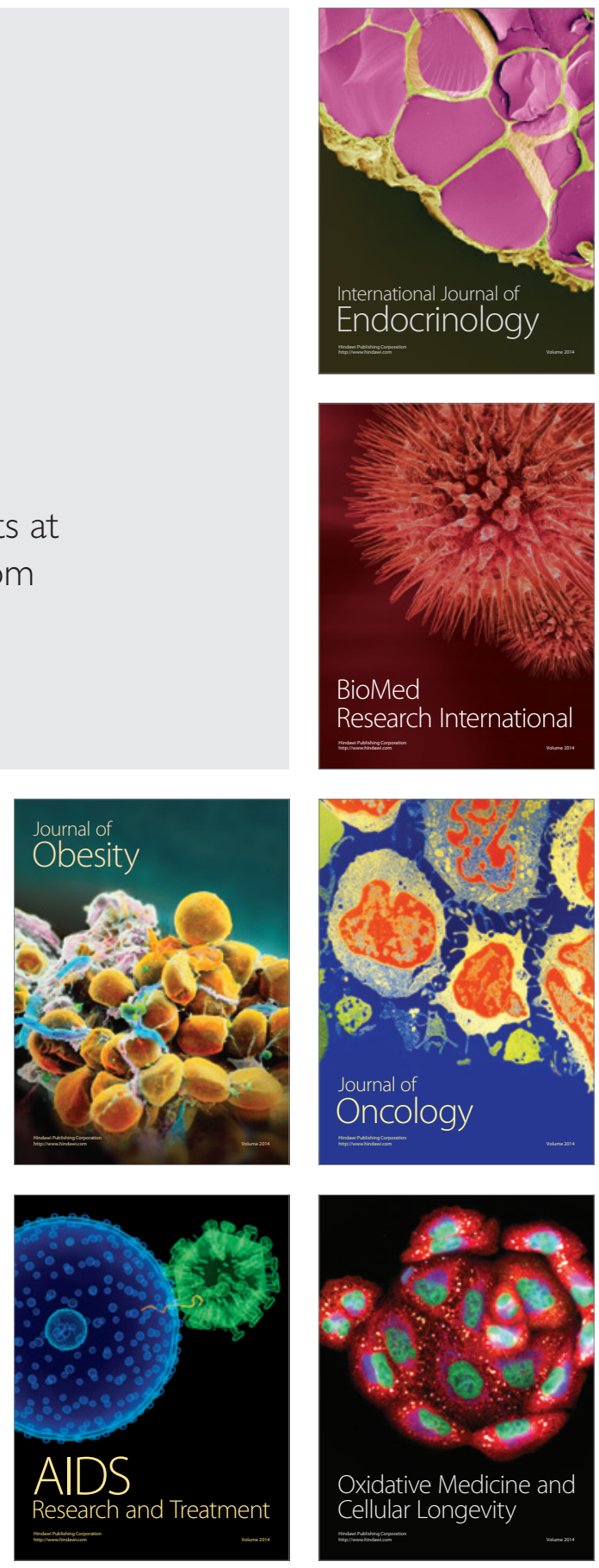